\title{
Embolia pulmonar por cianoacrilato pos embolización de malformación arteriovenosa cerebral. Caso clínico
}

\author{
Patricia Fernández ${ }^{1}$, Patricio Loayza ${ }^{2}$, Eduardo Sabbagh ${ }^{3}$, \\ Lautaro Badilla4, David Rojas², Gregorio Verschae ${ }^{5}$, \\ Beatriz Milet ${ }^{5}$.
}

\section{Cyanoacrylate pulmonary embolism after embolization of a cerebral arteriovenous malformation. Report of one case}

Arterial embolization with cyanoacrylate is commonly used for the treatment of arteriovenous malformations. We report the case of a 40 years old man who four days after an embolization with cyanoacrylate, begins with cough, bloody sputum, and right hemithorax pleuritic pain. Pulmonary embolism was confirmed with chest X ray, CT scan and scyntigraphy. The patient received anticoagulation, with adequate response. The most common complications of cerebral embolization are related to central nervous system and pulmonary embolism is exceptional. Considering the high number of embolization procedures done nowadays, this complication must be borne in mind (Rev Méd Chile 2004; 132: 489-92).

(Key Words: Cerebral embolism and thrombosis; Cyanoacrylates; Embolism and thrombosis)

Recibido el 25 de julio, 2003. Aceptado el 5 de diciembre, 2003.

${ }^{1}$ Departamentos de Medicina y ${ }^{3}$ Radiología, Instituto Nacional del Tórax. ${ }^{2}$ Departamento Neurocirugía Vascular y ${ }^{4}$ Servicio de Radiología, Instituto de Neurocirugía, Chile.

5Interno de Medicina Universidad de Chile.

$\mathrm{L}^{2}$ a embolización arterial con cianoacrilato es una técnica efectiva que permite la curación completa de un gran porcentaje de malformaciones arteriovenosas, con o sin la necesidad eventual de resección quirúrgica o radiocirugía. Esta técnica es utilizada en el manejo preoperatorio de aquellas

Correspondencia a: Patricia Fernández. Departamento de Medicina, Instituto Nacional del Tórax. Infante 717, Providencia, Santiago - Chile. Phone: 56-9-8713126. Fax: 56-2-2481092. E mail: pafeva99@hotmail.com malformaciones arteriovenosas de gran tamaño o cuando el riesgo quirúrgico es muy elevado.

No obstante, este procedimiento presenta complicaciones considerables, dentro de las cuales se describen la reacción alérgica al medio de contraste, perforación aneurismática, obliteración de arterias normales o embolia pulmonar, entre otras.

A continuación, se presenta el caso clínico de un paciente, que luego de una embolización arterial con cianoacrilato por una malformación arteriovenosa cerebral presenta síntomas y signos compatibles con una embolia pulmonar. 


\section{CASO CĹ́NICO}

Paciente de sexo masculino de 40 años de edad, sin antecedentes mórbidos de importancia. Fue ingresado al Instituto Nacional de Neurocirugía por historia de cefalea, vómitos y convulsiones de dos meses de evolución. Se realizó una tomografía axial computada (TAC) de encéfalo que demostró una malformación arteriovenosa frontal derecha de $6 \mathrm{~cm}$ de diámetro.

Debido a la extensión de la lesión y buscando reducir el riesgo operatorio, se efectuó una embolización arterial.

Este procedimiento se realizó con cianoacrilato diluido en lipiodol y tungsteno, como agente opacificador. Se obtuvo 60\% de oclusión de la malformación arteriovenosa, en un procedimiento sin incidentes (Figura 1). El paciente recibió esteroides durante las primeras $24 \mathrm{~h}$.

Al cuarto día postoperatorio, el paciente presentó tos, expectoración hemoptoica y dolor pleurítico en hemitórax derecho. Al examen físico, se encontró al paciente febril $\left(38,5^{\circ} \mathrm{C}\right)$, taquicárdico $(100 / \mathrm{min})$, con frecuencia respirato-

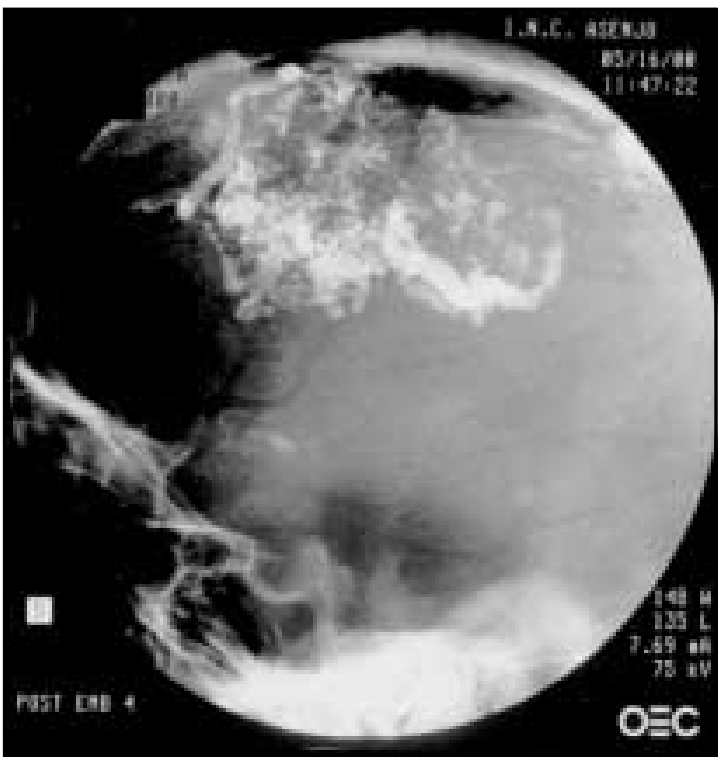

FiguRA 1. Arteriografía cerebral que muestra el material de embolización en el nido de la malformación arteriovenosa. ria de 30 por min. Los exámenes de laboratorio revelaron una insuficiencia respiratoria parcial $\left(\mathrm{PaO}_{2}: 60 \mathrm{mmHg}\right.$ recibiendo oxígeno $2 \mathrm{lt} / \mathrm{min}$ por naricera). La radiografía de tórax demostró múltiples imágenes radiopacas ocupando pequeños vasos, con una opacidad tenue con adherencia pleural derecha (Figura 2). La TAC de tórax reveló un derrame pleural izquierdo y algunos focos de condensación cortical de base pleural que no capturaron medio de contraste, sugerente de infartos pulmonares (Figuras 3 y 4 ). La cintigrafía de perfusión demostró defectos segmentarios y subsegmentarios múltiples, compatible con una alta probabilidad de embolia pulmonar. En consecuencia, se inició tratamiento anticoagulante con heparina intravenosa.

El paciente evolucionó afebril, sin dolor torácico, con disminución del requerimiento de oxígeno y reabsorción del derrame pleural. En definitiva, fue dado de alta en buen estado general, con un control a los tres meses sin síntomas respiratorios y con normalización de sus parámetros funcionales.

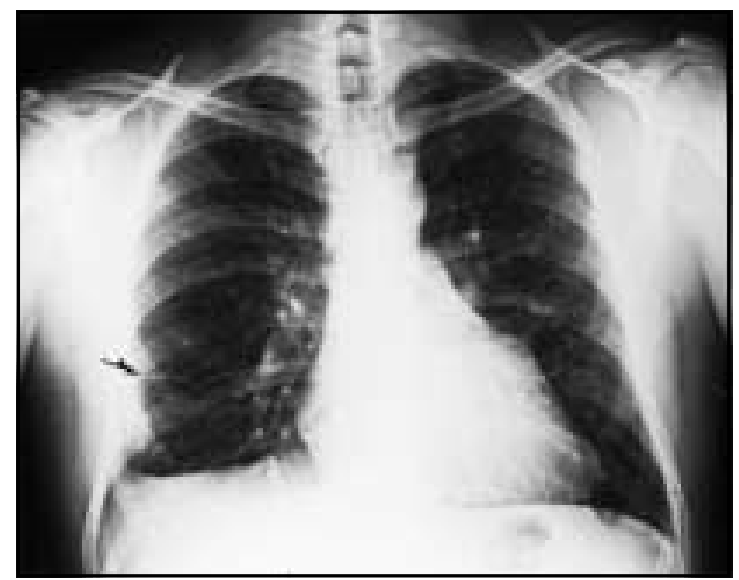

FIgURA 2. Radiografía de tórax posteroanterior. Se observan pequeñas áreas de consolidación y múltiples densidades radiológicas, representando embolia por cianoacrilato. 


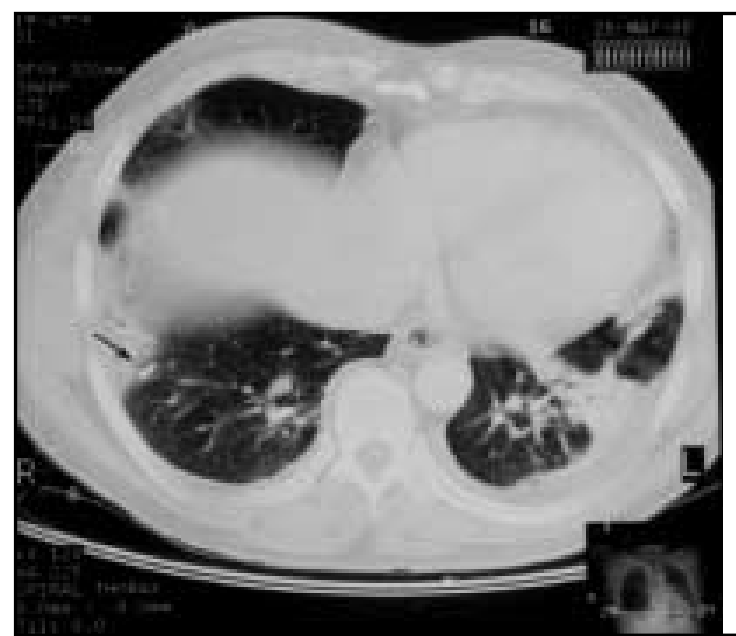

FIGURAS 3.

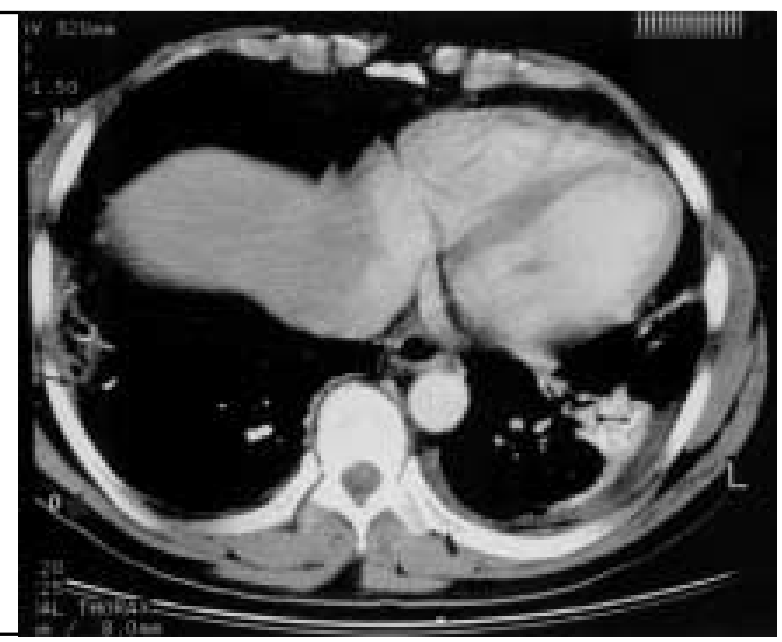

FIGURAS 4.

Figuras 3 y 4. Tomografía Axial Computada de Tórax realizada cinco días luego de la embolización arterial. Demuestra consolidación en ambos campos pulmonares inferiores, con múltiples densidades metálicas en los ápices de estas consolidaciones consistentes con embolia por cianoacrilato. Existe un derrame pleural izquierdo.

\section{DisCUSIÓN}

La embolización arterial de malformaciones arteriovenosas cerebrales ha sido ampliamente usada desde hace varias décadas. Para ello se han utilizado diferentes agentes, desde esponjas de gelatina que son reabsorbidas en días a semanas (Geolfam), agentes ocluyentes permanentes que inducen trombosis local (coils de platino, globos desechables o partículas de alcohol polivinílico), hasta agentes polimerizadores, siendo el más comúnmente usado el cianoacrilato. Esta sustancia comienza su polimerización en el instante en que entra en contacto con sangre o medio de contraste iónico.

Radiológicamente, las partículas de cianoacrilato tienen el aspecto de opacidades de una elevada densidad, similar a aquella de las partículas metálicas.

Se han comunicado complicaciones de este procedimiento, en su mayoría en relación al sistema nervioso central ${ }^{1}$. Estas incluyen desde la compresión de la vasa nervorum de pares craneanos hasta la perforación del mismo aneurisma. Existen escasas descripciones de embolia pulmonar como complicación posterior a la terapia intravascular de malformaciones arteriovenosas cerebrales.
Kjellin y $\mathrm{col}^{1}$ realizaron un estudio donde se evaluaron a 47 niños que habían recibido embolización arterial con diferentes materiales, entre ellos cianoacrilato, coils de platino, globos desmontables y alcohol polivinílico. La radiografía de tórax demostró depósito de material embólico en 10 pacientes con cianoacrilato y en 2 casos con coils de platino. Los pacientes presentaron una rápida mejoría clínica luego de 7 a 10 días de tratamiento conservador.

Es importante destacar que cuando un paciente se presenta con historia de embolización de una malformación arteriovenosa y falla respiratoria asociada debe descartarse, una embolia pulmonar por partículas extrañas ${ }^{4-6}$. Los síntomas de esta complicación incluyen: tos, disnea, dolor torácico pleurítico y hemoptisis. En algunas ocasiones se puede apreciar caída de la presión arterial de oxígeno. Pelz y $\mathrm{col}^{2}$ realizaron una revisión de fichas clínicas de 182 pacientes tratados por embolia por cianoacrilato, encontrando evidencia de complicaciones pulmonares; en tres casos se presentaron síntomas sugerentes de embolia pulmonar.

Por otra parte, estas complicaciones pueden llegar a presentarse de manera asintomática ${ }^{3-7}$; Kaplan describió el caso de una mujer que ingresó al servicio de medicina para evaluación 
de una malformación arteriovenosa cerebral. Se efectuó embolización arterial hace 19 años y nunca presentó sintomatología respiratoria. Sin embargo, casi 20 años después, en la radiografía de tórax se encontraron múltiples esferas de tamaño similar con densidad metálica, distribuidas aleatoriamente en ambos campos pulmonares ${ }^{3}$.

\section{REFERENCIAS}

1. KJEUN JB. Pulmonary emboli following therapeutic embolization of cerebral arteriovenous malformation in children. Pediatr Radiol 2000; 30: 279-83.

2. Pelz D, Lownie S, Fox A, Hutton L. Syntomatic pulmonary complications from liquid acrylate embolization of brain of arteriovenous malformation. Am J Neuroradiol 1995; 16; 19-26.

3. Kaplan V, Hauser M, Speich R. A patient with cerebral arteriovenous malformation and multiple metallic pulmonary particles. Chest 1996; 110: 1611-2.
En conclusión, la embolia pulmonar como complicación de técnicas intravasculares en malformaciones arteriovenosas cerebrales, es una patología que debe ser reconocida, especialmente con el incremento en el número de procedimientos realizados actualmente. A pesar de que muchos casos sean de presentación asintomática, y por lo tanto no sean pesquisados, pueden llegar a producir síntomas severos, incluyendo la muerte.

4. JN, Ryals TJ, Gavin JR, Loftus CM, Hunter JH. Pulmonary embolization and infarction. A iatrogenic complication transcatheter embolization of a cerebral arteriovenous malformation with polyvinil alcohol spongue. Chest 1993; 103: 1293-5.

5. McCarthy P, Kenedy A, Dawson P, Auson D. Pulmonary embolus as a complication of therapeutic peripheral arteriovenous malformation embolization. Br J Radiol 1991; 64: 177-8.

6. Carapiet DA, Stevens JE. Pulmonary embolism following embolization of an arteriovenous malformation. Paediatr Anaesth 1996; 6: 491-4.

7. TAKASUGi JE, SHAW C. Inadvertent bucrylate pulmonary embolization: a case report. J Thorac Imaging 1989; 4: 71-3. 